\title{
Research on Mental Health of Postgraduates in F University in China
}

\author{
Dongfang $\mathrm{Wan}^{1}$, \& Yasong Zhou ${ }^{2}$ \\ ${ }^{1}$ School of English for International Business, Guangdong University of Foreign Studies, Guangzhou, China; ${ }^{2}$ School of \\ Accounting, Guangdong University of Foreign Studies, Guangzhou, China. \\ Correspondence: Yasong Zhou, School of Accounting, Guangdong University of Foreign University, Guangzhou, China.
}

Received: June 1, 2020

Accepted: June 28, $2020 \quad$ Available online: June 29, 2020

doi:10.11114/ijsss.v8i4.4917

URL: https://doi.org/10.11114/ijsss.v8i4.4917

\begin{abstract}
This study investigates the mental health of 291 postgraduates in F University in China through Symptom Checklist-90 (known as SCL-90). The results show that $43.97 \%$ of the postgraduates suffer mental health problems of varying degrees, and a larger proportion of them are confronted with mild mental problems. The findings also reveal that the postgraduates score greatly higher than the SCL-90 National Norm of Chinese Adults in the four factors of compulsion, anxiety, terror and mental illness symptoms, while the two factors of interpersonal sensitivity and hostility are significantly lower. Besides, female postgraduates, English-related postgraduates and postgraduates from rural areas, whose mental health are worse, may be under greater pressure. This study would shed light on the relevant basis for further improvement of the postgraduates' mental health, and the corresponding countermeasures and suggestions for colleges and universities.
\end{abstract}

Keywords: postgraduates, mental health, SCL-90

\section{Introduction}

The number of postgraduates in China will reach 1.7 million and 2 million in 2015 and 2020 respectively, as the National Outline for Medium and Long-term Education Reform and Development (2010-2020) forecasts. With the expansion of the scale of talent cultivation, the mental health problems of postgraduates are becoming more and more prominent. Compared with undergraduates, postgraduates need to face pressures from the increasing academic difficulties, but also from employment, economy, marriage and other aspects. Besides, they are inevitably flooded by information of varying quality while enjoying the convenience brought by it in the era of information. Therefore, they need to devote more time and energy to distinguish and integrate information for their study, research, work and life. Excessive information beyond their ability to integrate will undoubtedly impair the capacity of postgraduates to create and maintain mental space, pushing them into a state of psychological exhaustion, which will seriously affect their mental health (Liu, 2020).

According to some surveys conducted by several universities in 2019, about $1 / 4$ of postgraduates are facing serious mental problems; the interpersonal relationship and anxiety index of postgraduates are significantly higher than the SCL-90 National Norm of Chinese Adults, which mainly resulted from employment prospect pressure, tuition concerns and their interest in learning content, etc.; the mental health of female postgraduates is obviously worse than male postgraduates; besides, those postgraduates from poor family show a lower level of mental health (Song et al., 2019; Zhang \& Huang, 2020; Xia, 2019; Zhang, 2019; Su, 2010; Xue, 2019).

The postgraduate period spans the two stages of life: late adolescence and early adulthood. According to Erickson's psychological development theory, these two life stages are the critical period for individuals to gain identity and establish true intimacy. Therefore, to provide support to the positive growth of individuals and the cultivation of social talents, colleges and universities must understand the current status of postgraduates' mental health and pay attention to the resolution of the mental problems.

Hence, with the expansion of postgraduate scale and increasing pressure of social competition, the practical difficulties and pressures that the postgraduates are confronted with in academics, employment, marriage and love, etc., are getting more severe so that their psychological problems are becoming more and more prominent. In recent years, postgraduates have frequently committed suicidal or murderous events due to mental problems or psychological factors. According to the research report on the college students in Hubei Province and many public media reports for the past few years, the suicide rate of postgraduates is higher than that of students from other school levels. In 2013, the case involving a medical postgraduate student, Lin Senhao, who poisoned his roommate Huang Yang at Fudan University in Shanghai, aroused 
great social concern about the mental health of postgraduates, which has become an important factor that directly affects the quality of postgraduate education, family health and social stability instead of individual phenomenon.

In response to the requirements of the Guidelines on Further Strengthening and Improving the Ideological and Political Education of Postgraduates, strengthening the mental health education and counseling for postgraduates becomes one of prior tasks for colleges and universities in China. On the basis of such a background, this study employed SCL-90 to evaluate the mental health of 291 postgraduates in F University in China, so as to provide references for other colleges to better carry out the mental health education for postgraduates.

\section{Research Methodology}

\subsection{Research Subjects}

In this study, a total of 308 postgraduate students aged from 21 to 33 from F University in China were surveyed, of which 291 valid questionnaires were taken back, with a recovery rate of $94.48 \%$. Among them, there are 63 boys and 225 girls except 3 students whose gender is not specified participating in questionnaire survey, 152 English-related majors and 139 non-English-related majors. Further, in total 291 participants, 142 participants are the only child in their family, 14 participants are from the single-parent family, and 186 participants are urban-household registration holders.

\subsection{Research Tool}

The SCL-90, compiled by Drogatis in 1975, consists of a total of 90 items, ranging from feeling, emotion, thinking, consciousness, behavior to lifestyle habits, interpersonal relationship, diet and sleep, etc., and employs 10 factors to reflect the psychological symptoms in 10 aspects. In this study, the mental health level of postgraduates was evaluated using nine sub-scales or factors except diet and sleep in this scale, namely somatization, compulsion, interpersonal sensitivity, depression, anxiety, hostility, terror, paranoia and mental illness, each of which adopted a 5-level scoring system. The higher the score, the more serious the factor. The Cronbach a coefficient of this study was 0.97 .

\subsection{Data Collection Process}

The survey was conducted in a centralized manner with the class as the survey unit. Postgraduate counselors of each class acted as examiners and guided them to fill in the questionnaires in unified instructions, which was lasting for 20 minutes.

\subsection{Statistical Processing Method}

All the data in this study were processed by SPSS 22.0, mainly including descriptive statistics, T-test, F-test and correlation analysis.

\section{Research Results}

\subsection{SCL-90 Screening Results}

The screening standard for this evaluation is that the single factor is greater than or equal to 2 points $(\geq 2)$, and the severity of each symptom is classified as mild, moderate and severe according to the rating criteria of $2 \sim 3$ points, 3 4 points, and 4 points or more. The results are shown in the following table after statistical screening (See Table 1). It turns out that the detection rate of mental problems of postgraduates is $43.97 \%$, of which 104 sustain mild mental problems, accounting for $35.74 \%$; 21 are subjected to moderate mental problems, accounting for $7.22 \%$. Besides, there are 3 postgraduates suffering severe psychological distress, accounting for $1.03 \%$ of the total number. The detection rate of single factor of compulsion, depression and interpersonal sensitivity is relatively high respectively.

Table 1. The SCL-90 indicator screening results of postgraduates

\begin{tabular}{|c|c|c|c|c|c|c|c|c|}
\hline \multirow{2}{*}{ Items } & \multicolumn{2}{|l|}{ Mild } & \multicolumn{2}{|c|}{ Moderate } & \multicolumn{2}{|c|}{ Severe } & \multicolumn{2}{|l|}{ Total } \\
\hline & N. & $\%$ & $\mathrm{~N}$. & $\%$ & $\mathrm{~N}$. & $\%$ & $\mathrm{~N}$. & $\%$ \\
\hline Somatization & 19 & 6.52 & 5 & 1.72 & 0 & 0.00 & 24 & 8.52 \\
\hline Compulsion & 92 & 31.62 & 9 & 3.09 & 2 & 0.68 & 103 & 35.40 \\
\hline $\begin{array}{l}\text { Interpersonal } \\
\text { sensitivity }\end{array}$ & 48 & 16.49 & 9 & 3.09 & 2 & 0.68 & 59 & 20.27 \\
\hline Depression & 53 & 18.21 & 5 & 17.18 & 1 & 0.34 & 59 & 20.27 \\
\hline Anxiety & 42 & 14.43 & 4 & 13.75 & 1 & 0.34 & 47 & 16.15 \\
\hline Hostility & 34 & 11.68 & 5 & 17.18 & 0 & 0.00 & 39 & 13.40 \\
\hline Terror & 21 & 7.22 & 7 & 24.05 & 0 & 0.00 & 28 & 9.62 \\
\hline Paranoia & 41 & 14.09 & 1 & 0.34 & 0 & 0.00 & 42 & 14.43 \\
\hline Mental illness & 25 & 8.59 & 5 & 17.18 & 0 & 0.00 & 30 & 10.31 \\
\hline Any one symptom & 104 & 35.74 & 21 & 7.22 & 3 & 1.03 & 128 & 43.97 \\
\hline
\end{tabular}

Note: Mild $=2$ points $\leq$ the factor score $<3$ points, Moderate $=3$ points $\leq$ the factor score $<4$ points, Severe $=$ the factor 
score $\geq 4$ points; Total refers to the sum of the number of mild, moderate and severe; Any one symptom means the number of participants and the percentage of any factor with equal to or more than 2 points.

The comparative results of the 9 factors of SCL-90 in this case study and the SCL-90 National Norm of Chinese Adults (hereinafter National Norm of Adults) show that the scores of the four factors of compulsion, anxiety, terror and mental illness are significantly higher than that of the National Norm of Adults, while the scores of interpersonal sensitivity and hostility are greatly lower than that of the National Norm of Adults (See Table 2).

Table 2. The comparative scores of SCL-90 for postgraduates in this study and the SCL-90 National Norm of Chinese Adults

\begin{tabular}{lccc}
\hline Items & $\begin{array}{l}\text { Postgraduate } \\
\text { students } \\
(\mathrm{n} .=291)\end{array}$ & $\begin{array}{l}\text { National Norm of } \\
\text { Adults } \\
(\mathrm{n} .=1338)\end{array}$ & T-value \\
\hline Somatization & $1.35 \pm 0.44$ & $1.37 \pm 0.48$ & -0.70 \\
Compulsion & $1.79 \pm 0.62$ & $1.62 \pm 0.58$ & $4.67^{* * *}$ \\
Interpersonal Sensitivity & $1.57 \pm 0.59$ & $1.65 \pm 0.61$ & $-2.37^{*}$ \\
Depression & $1.53 \pm 0.54$ & $1.50 \pm 0.59$ & 0.81 \\
Anxiety & $1.49 \pm 0.52$ & $1.39 \pm 0.43$ & $3.44^{* * *}$ \\
Hostility & $1.38 \pm 0.47$ & $1.46 \pm 0.55$ & $-2.62^{* *}$ \\
Terror & $1.34 \pm 0.47$ & $1.23 \pm 0.41$ & $4.18^{* * *}$ \\
Paranoia & $1.38 \pm 0.45$ & $1.43 \pm 0.57$ & -1.62 \\
Mental illness & $1.38 \pm 0.44$ & $1.29 \pm 0.42$ & $3.59^{* * *}$ \\
\hline
\end{tabular}

Note: $* p<0.05,{ }^{*} p<0.01,{ }^{* * *} p<0.001$, similarly he

Oreinafter.

\subsection{Difference Tests}

\subsubsection{Difference Test of Gender}

In terms of gender, the mean values of the 9 factors, such as somatization and compulsion, are significantly higher in female students than in male students as Table 3 presents, which is consistent with statistically significant difference. In other words, male students have higher mental health level than female students who are more likely to show somatization, compulsion, interpersonal sensitivity, depression, anxiety, hostility, fear, paranoia, mental illness and other symptoms.

Table 3. Difference test of gender

\begin{tabular}{llll}
\hline Items & $\begin{array}{l}\text { Male } \\
\mathrm{M} \pm \mathrm{SD}\end{array}$ & $\begin{array}{l}\text { Female } \\
\mathrm{M} \pm \mathrm{SD}\end{array}$ & T-value \\
\hline Somatization & $1.20 \pm 0.30$ & $1.40 \pm 0.47$ & $-3.15^{* *}$ \\
Compulsion & $1.51 \pm 0.52$ & $1.88 \pm 0.62$ & $-4.16^{* * *}$ \\
Interpersonal & $1.34 \pm 0.40$ & $1.64 \pm 0.62$ & $-4.03^{* * *}$ \\
sensitivity & $1.29 \pm 0.38$ & $1.60 \pm 0.56$ & $-3.86^{* * *}$ \\
Depression & $1.28 \pm 0.33$ & $1.56 \pm 0.55$ & $-2.26^{*}$ \\
Anxiety & $1.27 \pm 0.46$ & $1.42 \pm 0.48$ & $-3.42^{* * *}$ \\
Hostility & $1.17 \pm 0.28$ & $1.39 \pm 0.50$ & $-3.29^{* * *}$ \\
Terror & $1.23 \pm 0.35$ & $1.44 \pm 0.47$ & $-3.34^{* * *}$ \\
Paranoia & $1.23 \pm 0.30$ & $1.43 \pm 0.47$ & $-3.73^{* * *}$ \\
Mental illness & 291 & & \\
Total N. & & &
\end{tabular}

\subsubsection{Difference Test of Major}

On major dimension, a significant difference lies in mental health between English-related majors and non-English-related majors. It can be seen from the following table that the mental health level of English-related majors, showing more somatic and psychotic symptoms, etc., is worse than that of non-English-related majors who show lower levels of these symptoms. 
Table 4. Difference test of major

\begin{tabular}{llll}
\hline Items & $\begin{array}{l}\text { English-related } \\
\text { majors } \\
\mathrm{M} \pm \mathrm{SD}\end{array}$ & $\begin{array}{c}\text { Non-English-related } \\
\text { majors } \\
\mathrm{M} \pm \mathrm{SD}\end{array}$ & T-value \\
\cline { 2 - 4 } Somatization & $1.44 \pm 0.48$ & $1.25 \pm 0.37$ & $3.63^{* * *}$ \\
Compulsion & $1.98 \pm 0.61$ & $1.58 \pm 0.57$ & $5.71^{* * *}$ \\
Interpersonal & $1.73 \pm 0.65$ & $1.39 \pm 0.45$ & $5.19^{* * *}$ \\
sensitivity & $1.68 \pm 0.58$ & $1.36 \pm 0.45$ & $5.14^{* * *}$ \\
Depression & $1.62 \pm 0.56$ & $1.36 \pm 0.43$ & $4.32^{* * *}$ \\
Anxiety & $1.49 \pm 0.51$ & $1.27 \pm 0.40$ & $4.11^{* * *}$ \\
Hostility & $1.45 \pm 0.54$ & $1.23 \pm 0.36$ & $4.14^{* * *}$ \\
Terror & $1.50 \pm 0.49$ & $1.26 \pm 0.35$ & $4.44^{* * *}$ \\
Paranoia & $1.66 \pm 0.52$ & $1.38 \pm 0.43$ & $4.87^{* * *}$ \\
Mental illness & 291 & & \\
Total N. & & & \\
\hline
\end{tabular}

\subsubsection{Difference Test of Only Child or not}

There is no significant difference between only child and non-only child in 9 factors of mental health evaluation for postgraduates.

\subsubsection{Difference Test of Family Structure}

The influence of family structure on 9 factors of mental health evaluation for postgraduates is not significant in this research.

\subsubsection{Difference Test of Household Registration}

As can be seen from Table 5, the mental health level of postgraduates from urban areas is significantly different from that of postgraduates from rural areas. The rural household registration holders (postgraduates) might suffer more severe psychological distress, appearing higher level of symptoms like compulsion, interpersonal sensitivity, depression, etc..

Table 5. Difference test of household registration

\begin{tabular}{llll}
\hline Items & $\begin{array}{l}\text { Urban household } \\
\text { registration } \\
\mathrm{M} \pm \mathrm{SD}\end{array}$ & $\begin{array}{l}\text { Rural household } \\
\text { registration } \\
\mathrm{M} \pm \mathrm{SD}\end{array}$ & T-value \\
\cline { 2 - 4 } Somatization & $1.29 \pm 0.34$ & $1.47 \pm 0.57$ & $-3.34^{* * *}$ \\
Compulsion & $1.71 \pm 0.58$ & $1.95 \pm 0.66$ & $-3.24 * * *$ \\
Interpersonal & $1.50 \pm 0.52$ & $1071 \pm 0.68$ & $-2.96^{* *}$ \\
sensitivity & $1.45 \pm 0.47$ & $1.67 \pm 0.63$ & $-3.43^{* * *}$ \\
Depression & $1.42 \pm 0.46$ & $1.63 \pm 0.59$ & $-3.39^{* * *}$ \\
Anxiety & $1.35 \pm 0.46$ & $1.47 \pm 0.50$ & $-2.11^{*}$ \\
Hostility & $1.28 \pm 0.40$ & $1.47 \pm 0.56$ & $-3.26^{* * *}$ \\
Terror & $1.35 \pm 0.41$ & $1.47 \pm 0.50$ & $-2.13^{*}$ \\
Paranoia & $1.33 \pm 0.39$ & $1.48 \pm 0.51$ & $-2.75^{* *}$ \\
Mental illness & 291 & & \\
Total N. & & & \\
\hline
\end{tabular}

\section{Research Analysis and Discussion}

A quantitative analysis of 9 factors of mental health evaluation for postgraduates has been conducted with the assistance of SCL-90 and SPSS in the preceding part. The results demonstrate that the mental health situation of postgraduates in F University is less than promising. Specifically speaking, 43.97\% of postgraduates are detected positive for mental problems, among which, those with mild and moderate mental distress account for $35.74 \%$ and $8.25 \%$ of the total number respectively. In other words, nearly half of the postgraduates in the research may suffer some degree of mental health problems. Compared with the National Norm of Adults, it is found that the postgraduates in F University tend to be able to better deal with others and show less hostility to others, which is attributed to the inclusive, open and free campus atmosphere in F University. However, the scores of postgraduates in compulsion, anxiety, terror and mental illness were relatively high, caused by the heavy academic task, great research pressure and high employment expectation of postgraduates. Therefore, the development of mental health for the postgraduates must be paid more attention and the psychological counseling should be conducted reasonably and timely so as to improve their mental health level.

Consistent with the previous researches, female postgraduates face more serious mental problems. In addition to coping with 
academic and scientific research, and economic issues, female postgraduates have to face greater challenges in employment due to age and the expectations for social role. Compared with male postgraduates, they need to spend more time and effort to achieve their goals, which would lead to greater mental pressure and lower mental health (Deng \& $\mathrm{Hu}, 2019$ ).

Besides, the mental health level of postgraduates whose majors are related to English is lower. On one hand, with the development of social economy and the popularization of English education, the advantage of English-related majors is gradually dwindling due to the improvement of English proficiency of postgraduate students; on the other hand, English-related majors now face more severe employment pressure caused by the weakening economic situation and the increasingly fierce social competition. F University is one of the traditional famous language universities in China, whose English-related majors account for about half of the total students. Therefore, it is particularly important to change the current situation of how to properly guide English-related majors to cultivate compound talents.

What is noteworthy is that postgraduates from rural areas show extremely low level of mental health compared with those from cities. Based on the theory of social resources, the postgraduates from rural areas possess less available social resources in various aspects, such as professional knowledge, breadth of knowledge, network resources and social support, etc., compared with those from cities. Most postgraduates from rural areas are poor and they have to do some part-time jobs to pay high tuition fees. In addition, relatives of poor postgraduates can't help them solve practical difficulties and provide timely psychological support due to low education level. All these have resulted in the greater difficulty and psychological pressure for postgraduates from rural areas, leading to lower mental health level. The results remind the university not only to offer material support but also to provide psychological counseling to the postgraduates.

\section{Suggestions and Countermeasures}

As an indispensable part of postgraduate education, the mental health education for postgraduates should be regarded as one of the priorities of colleges and universities. Authorities in colleges and universities in China ought to realize the importance and necessity of mental health education for postgraduates and take effective measures to strengthen and improve it. On the basis of the current study, several concrete suggestions are given for the mental health education for postgraduates in the future.

Firstly, colleges and universities need to incorporate mental health education into the postgraduate talent education system. Different from attaching great importance to mental health education for undergraduates, the mental health education is often neglected in the postgraduate education system at present, resulting in the lack of necessary understanding of mental health knowledge among postgraduates' supervisors, ideological and moral teachers for postgraduates moral and even postgraduates themselves. Therefore, colleges and universities should take the initiative to integrate the mental health education for postgraduates into all aspects of postgraduates' education, such as offering mental health courses and lectures, carrying out mental health survey, providing psychological counseling, conducting crisis intervention work and constantly innovating and enriching teaching means and carriers, etc., so as to practically improve the effectiveness of mental health education.

Secondly, Efforts should be made to form a three-in-one operating mechanism of "university psychological counseling center --- postgraduates' supervisor --- college counselor". Practice has proven that psychological counseling and treatment is an important and effective way to solve mental problems, especially general mental problems. The university should integrate resources to clarify the status and functions of psychological counseling center for college students through emphasizing the integration of psychological health education for undergraduates and postgraduates so as to better play the role of the counseling center. More importantly, colleges and universities should strengthen the mental health training of postgraduates' supervisors and give full play to the role of them in psychological consultation for postgraduates. The teaching and the educating are the two basic duties of the supervisor. Supervisors need not only to offer guidance in postgraduates' studies, but also to care about the comprehensive growth of postgraduates, including the ideological status and mental health, etc., and help them to solve the difficulties in their study and life, so as to actively build up harmonious relationship with students. In addition, with the continuous expansion of postgraduate scale, the colleges and universities also should build a team of full-time graduate counselors with discipline, moral integrity and exquisite professional work through combining with actual demand and strengthening training, which would lay a good foundation for the ideological and political education, mental health education, employment and other aspects for postgraduates.

Thirdly, the enthusiasm and initiative of postgraduates should be given full play and be mobilized. Postgraduates, by contrast, are more mature in both physical and psychology, more knowledgeable and more stable in values than graduate students. Hence, the initiative of postgraduates' self-education should be exerted to make it self-regulate and self-develop in addition to the taught psychological course. On the one hand, it is necessary to guide postgraduates to strengthen self-discipline in psychology so as to learn to make self-psychological adjustment; on the other hand, colleges and universities should develop postgraduate campus culture and enrich their extra-curricular life, including carrying out more academic, artistic and recreational activities that postgraduates like, which is conducive to changing the monotonous and dull life and study style, 
cultivating sentiments, and promoting mutual communication so as to improve the mental health of postgraduates.

Lastly, targeted crisis intervention should be conducted to effectively solve the practical problems of postgraduates. As this study found, nearly half of the postgraduates suffered some degree of mental health problems, among which female postgraduates, English-related majors and those with rural household registration may be under greater pressure. Consequently, colleges and universities should actively create conditions to exert their greatest effort to help resolve the practical difficulties postgraduates face based on the actual situation. More importantly, in order to improve the effectiveness of crisis intervention, a sound crisis intervention system should be established to tack with the psychological crisis when it comes to postgraduates.

\section{Conclusion}

To sum up, the study reveals that more than $40 \%$ of the postgraduate students suffer differential mental health problems, which is far more than promising. Chinese college and universities should pay more attention to their postgraduates' mental health and take effective measures to build a sound mental health system so as to enhance the quality of graduate education.

\section{References}

Chinese Ministry of Education. (2010). Guidelines on Further Strengthening and Improving the Ideological and Political Education of Postgraduate. Retrieved November 17, 2010, from http://www.moe.edu.cn/publicfiles/business/htmlfiles/moe/s6875/201210/142974.htm

Chinese Ministry of Education. (2010). National Outline for Medium and Long-term Education Reform and Development (2010-2020). Retrieved from http://www.gov.cn/jrzg/2010-07/29/content-1667143/htm,2010-07-29

Deng, J., \& Hu, R. F. (2019). An Analysis of the Factors Influencing the Anxiety Psychology of Female Postgraduates at School based on Grounded Theory. Statistics and Management, 05, 88-92.

Derogtis, L. R. (1975). How to use the Syston Distrss Checklist (SCL-90) in clinical evaluations, Psychiatric Rating Scale, Vol 3. Self-Report Rating Scale. Hoffmann-La Roche Inc, 1975, 22-26.

Hubei Provincial Department of Ideological and Political Education, Social Research Office and Hubei Provincial Mental Health Education Center for Youth. (2008). A brief report on the suicide of college students in Hubei Province. 2008, 234-240.

Lin, Y. Y. (2005). Exploration on Postgraduates' mental health education. Journal of Fujian Normal University, 04, $142-145$.

Liu, Z. Z. (2020). On the spectrum of mental health education pattern for postgraduates.China Journal of Health Psychology, 6, 1-6. https://kns.cnki.net/kcms/detail/11.5257.R.20200611.1316.002.html

Ma, X. T., \& Li, W. H. (2011). An Investigation into Graduate Students' Mental health and life stress . Chinese Journal of Special Education, 04, 91-95.

Su, Y. Q., Liu, P., \& Zhu, X. S. (2010). Mentality Health Situations and Education Suggestions of the Postgraduate in University of Technology. Journal of Chengdu University of Technology (Social Sciences), 18(1), 87-91.

Sun, Y. (2006). The problems and countermeasures of mental health education for postgraduates.China Higher Education Research, 11, 38-39.

Wen, S. F., \& Yu, G. L. (2008). Mental health education for postgraduates:current status, problems and countermeasures. Studies in Ideological Education, 5, 61-63.

Xia, X. X., Shen, J. Z., \& Liu, D. (2019). An Empirical Research on the Comprehensive Health of the Graduate Students in China. Journal of National Academy of Education Administration, 8, 89-95.

Xue, M. X., \& Shu, M. (2019). Relationship between Mental Health, Life Satisfaction and Psychological Flexibility of Postgraduates. Journal of Zhejiang Industry \& Trade Vocational College, 19(4), 69-72.

Zhang, H. M., Wang, F. R., Chen, G., \& Yang, H. Q. (2019). Investigation and Analysis of the Mental Health of Postgraduates in Military Academies. Journal of Higher Education Research, 42(4), 73-80.

\section{Copyrights}

Copyright for this article is retained by the author(s), with first publication rights granted to the journal.

This is an open-access article distributed under the terms and conditions of the Creative Commons Attribution license which permits unrestricted use, distribution, and reproduction in any medium, provided the original work is properly cited. 